\title{
ANÁLISE GEOQUÍMICA DE ROCHAS SEDIMENTARES ARGILOSAS A PARTIR DO CONTEÚDO DOS ELEMENTOS MAIORES, PERDA AO FOGO E DIFRAÇÃO DE RAIOS X
}

\author{
GEOCHEMICAL ANALYSIS OF CLAYISH SEDIMENTARY ROCKS FROM THE CONTENTS OF \\ MAJOR ELEMENTS, LOSS ON IGNITION AND X-RAY DIFFRACTION \\ Maria Margarita TORRES ${ }^{1}$, Sérgio Ricardo CHRISTOFOLETTI ${ }^{2}$, Diego de Souza \\ SARDINHA $^{3}$, Letícia Hirata GODOY ${ }^{3}$ \\ ${ }^{1}$ Depto de Petrologia e Metalogenia- IGCE- UNESP- Univ. Estadual Paulista. Email:mmoreno@rc.unesp.br \\ ${ }^{2}$ Instituto Florestal - Governo do Estado de São Paulo. Email: sergioricardoc@gmail.com \\ ${ }^{3}$ Universidade Federal de Alfenas-Poços de Caldas. Emails: diego.sardinha@unifal-mg.edu.br; leticiahirata@gmail.com
}

\author{
Introdução \\ Procedimento Experimental \\ Resultados e Discussão \\ Conclusões \\ Referências
}

\begin{abstract}
RESUMO - Foram realizados estudos geoquímicos em rochas sedimentares argilosas da Formação Corumbataí - unidade geológica da Bacia do Paraná, utilizadas como matéria prima na obtenção de produtos cerâmicos, objetivando extrair informações a partir das análises químicas dos elementos maiores aliadas às descrições de campo. Através destas informações foi possível estabelecer diferenças e similaridades entre os estratos argilosos de três minerações localizadas em diferentes municípios da região estudada. Foi dada especial importância à perda ao fogo, uma vez que esta determinação resulta principalmente da liberação de $\mathrm{CO}_{2}$ e/ou água durante o aquecimento a $1000^{\circ} \mathrm{C}$. As relações usadas para óxidos/elementos químicos, quando lançadas em gráficos, mostram agrupamentos e/ou sequências resultantes da proporção, tipos de componentes e estados de alteração dos materiais amostrados, o qual foi verificado mediante análise por difração de raios X. Também foi abordado o efeito fundente de certos elementos a temperaturas maiores que $1000^{\circ} \mathrm{C}$ tais como sódio, o qual pode modificar o comportamento observado quando se usa como variável a perda ao fogo.
\end{abstract}

Palavras-chave: rochas sedimentares; geoquímica; argilas; cerâmica.

\begin{abstract}
Geochemical studies were performed in clayish sedimentary rocks from Corumbataí Formation, a Paraná Basin geological unit, used as raw material for ceramic products, in order to extract information from major elements chemical analysis along with field descriptions. Through these data, variations and similarities were established among the clayish strata of three mines located in distinct municipalities of the studied region. Special attention was given to the loss on ignition, since it results mainly from the $\mathrm{CO}_{2}$ and/or water release during heating at $1000^{\circ} \mathrm{C}$. The used oxides/chemical elements ratios, when plotted, show clusters and/or sequences that results from proportion, component types and weathering state of the sampled materials, which was verified by X-ray diffraction analysis. Thus fluxing effect of certain elements at temperatures greater than $1000^{\circ} \mathrm{C}$ was evaluated, such as sodium, which can modify the observed behavior when loss on ignition is used as the variable.

Keywords: sedimentary rocks; geochemistry; clays; ceramics.
\end{abstract}

\section{INTRODUÇÃO}

A Formação Corumbataí constitui uma unidade geológica da Bacia do Paraná de grande importância econômica por ser um dos maiores depósitos de matéria prima para a indústria cerâmica de revestimento.

As rochas ricas em aluminossilicatos geram argilominerais pela ação de agentes mecânicos (hídricos, eólicos, tectônicos e glaciares) e químicos (água, gás carbônico, ácidos orgânicos, etc.) se desagregam, e as partículas ao serem transportadas são submetidas à segregação durante o percurso, podendo formar grandes depósitos ao se acumular ao longo do tempo (Barba et al, 1997).

Novas transformações ocorrem devido a processos de compactação, diagênese e muitas vezes hidrotermalismo, resultando em rochas sedimentares argilosas. Estas rochas são submetidas a alterações por agentes intempéricos concentrando determinados componentes por modificações mecânicas, precipitação química, lixiviação e alterações térmicas (Van Vlack, 1973).

Estes materiais têm sua aplicação principalmente na indústria cerâmica gerando produtos de diversos tipos e consistem em misturas de argilominerais e outros tipos de minerais em diferentes proporções que, dependendo de seu uso, podem requerer tratamentos específicos de beneficiamento.

A análise química é muito utilizada como um dos parâmetros de controle das matérias primas argilosas ou argilas naturais. A dificuldade em extrair informações reside na complexidade da composição dos espécimes envolvidos, tanto pelo número dos mesmos quanto pelos átomos componentes de um espécime, principalmente os argilominerais, 
onde diferentes átomos com raio iônico semelhante podem ocupar um determinado sítio na estrutura cristalina, que pode levar ao desequilíbrio das cargas opostas, as quais são compensadas admitindo outros elementos (Fauer, 1991), por outra parte, um mesmo elemento pode fazer parte da estrutura de diferentes compostos dificultando o entendimento dos resultados da análise.

A perda ao fogo é obtida a partir do aquecimento a $1000^{\circ} \mathrm{C}$ de uma amostra seca a $100^{\circ} \mathrm{C}$ significando que, em geral, o conjunto de voláteis corresponde principalmente à água formada a partir das hidroxilas dos argilominerais e hidróxidos de ferro e alumínio, ao $\mathrm{CO}_{2}$ quando os carbonatos estão presentes e em menor proporção a compostos voláteis abaixo de $1000^{\circ} \mathrm{C}$ tais como matéria orgânica, sulfetos, sulfatos e restos de água não liberados a $100^{\circ} \mathrm{C}$ por determinados argilominerais (Souza Santos, 1989). Na fabricação de produtos cerâmicos são aplicadas temperaturas elevadas visando unir as partículas formando uma massa coesa (sinterização), o que implica em transformações decorrentes de reações de desidratação, desidroxilação, decomposição, vitrificação e formação de novos componentes como resultado da movimentação dos átomos, a qual depende principalmente da compactação das partículas, dos componentes envolvidos e das temperaturas aplicadas.

Como resultado, as alterações correspondem a peso, volume, porosidade, área específica dos grãos e da massa total e modificação das propriedades (Van Vlack, 1973). O conteúdo de carbonatos na mistura para obtenção de um determinado produto pode modificar curso das reações que ocorrem a altas temperaturas, gerando fases cristalinas diferentes às que ocorreriam sem a presença dos mesmos, afetando as propriedades esperadas.

A presença elevada de carbonatos aumenta a porosidade e retarda a sinterização decorrente da formação de uma fase líquida, porém, de acordo com Barba et al (1997) em testes com aumento progressivo de $\mathrm{CaCO}_{3}$, uma vez iniciada a sua participação na formação da fase líquida, a velocidade de sinterização é maior em relação à mesma massa sem adição de carbonato.

O objetivo principal deste trabalho consiste na análise geoquímica de amostras da Formação Corumbataí, obtidas em três minerações de argila na região de Rio Claro (SP). Para tanto foram estabelecidas relações entre parâmetros indicativos das variações na composição química decorrentes de alterações ou transformações na mineralogia, provocados por processos geológicos envolvendo circulação de fluídos resultantes da evolução dos materiais iniciais, provocando movimentação diferenciada dos elementos químicos.

A perda ao fogo (PF) inclui os gases liberados após a decomposição/transformação de determinados componentes a $1000^{\circ} \mathrm{C}$ (carbonatos, perda de cristalinidade dos argilominerais liberando água a partir das hidroxilas ( $\mathrm{OH}-)$, matéria orgânica, sulfetos e sulfatos, principalmente), desta forma, para este estudo a PF é uma variável importante, assim como os elementos com maior mobilidade tais como sódio, cálcio, silício e potássio ou os elementos menos móveis, tais como alumínio, ferro e titânio.

\section{PROCEDIMENTO EXPERIMENTAL}

Foram selecionadas três minerações onde o critério principal foi a sua localização em diferentes municípios, estarem ativas e conter carbonatos em determinados níveis. Estas foram denominadas: mineração (ML) localizada no município de Limeira, mineração (MA), município de Araras e mineração (MR) no município de Rio Claro (Figura 1).

Inicialmente foram realizados trabalhos de campo para ser feita a descrição das minerações através de perfis verticais e posteriormente a coleta de amostras na forma de calha. Estas amostras foram processadas para a realização de análise química, mineralógica e cerâmica.

A análise química dos elementos maiores, reportada na forma de óxidos $\left(\mathrm{SiO}_{2}, \mathrm{TiO}_{2}\right.$, $\mathrm{Al}_{2} \mathrm{O}_{3}, \mathrm{Fe}_{2} \mathrm{O}_{3}, \mathrm{MnO}, \mathrm{MgO}, \mathrm{CaO}, \mathrm{Na}_{2} \mathrm{O}, \mathrm{K}_{2} \mathrm{O}$ e $\mathrm{P}_{2} \mathrm{O}_{5}$ ), foi realizada por Espectrometria de Fluorescência de Raios X (Phillips, modelo PW 2510) em amostras fundidas em matriz de borato, no Laboratório de Geoquímica da UNESP-Rio Claro. A perda ao fogo (PF) foi medida por diferença de peso após calcinação a $1000^{\circ} \mathrm{C}$ da amostra seca.

A mineralogia foi obtida por difração de raios X (equipamento SIEMENS D5000) - 
radiação $\mathrm{CoK} \alpha$ e filtro de ferro. As determinações foram feitas na amostra total e a fração menor que duas micras, obtida por desagregação da amostra moída em água deionizada e posterior sedimentação segundo a Lei de Stokes (Reed, 1995). A suspensão contendo a fração menor que $2 \mu \mathrm{m}$ foi extraída por centrifugação e depositada em lâminas de vidro (adquirindo orientação preferencial) e posteriormente analisadas na sua forma natural, tratadas com etilenoglicol durante $48 \mathrm{~h}$ e queimadas a $500^{\circ} \mathrm{C}$. Para a caracterização cerâmica as amostras foram secas a $60^{\circ} \mathrm{C}$ em estufa por $24 \mathrm{~h}$ e moídas em moinho de martelos de laboratório com peneira de $1 \mathrm{~mm}$. Posteriormente foram granuladas em torno de $8 \%$ de umidade, condicionadas individualmente em saco plástico com o mínimo de ar e deixadas em descanso por 24 horas para homogeneização. A prensagem dos corpos de prova foi realizada em molde de $7 \times 2 \mathrm{~cm}$, utilizando aproximadamente $19 \mathrm{~g}$ de massa, de tal forma que a densidade das peças verdes ficasse próxima de $1,8 \mathrm{~g} . \mathrm{cm}^{-3}$, determinando se a umidade e densidade de prensagem.

A queima foi realizada em forno de laboratório com controle de temperatura (Maitec - modelo FE50RP) permanecendo dois minutos na temperatura máxima $\left(1070^{\circ} \mathrm{C}\right.$ e $\left.1120^{\circ} \mathrm{C}\right)$.

Nestas condições foi determinada a absorção de água (AA) e densidade após queima (ABNT, 1997) de cinco corpos de prova obtendo assim o valor médio.

\section{RESULTADOS E DISCUSSÃO}

Na área de estudo (Figura 1) está localizado o maior pólo cerâmico de revestimentos do Brasil, onde a maioria das indústrias obtém o produto, por moagem a seco, utilizando rochas sedimentares da Formação Corumbataí aflorantes na região. Estes materiais são considerados de boa qualidade, pois permitem a obtenção de produtos com sinterização adequada a temperaturas relativamente baixas se comparadas ao processo de fabricação por moagem a úmido. Foram estudadas três minas localizadas em torno do município de Santa Gertrudes o qual deu origem ao nome "Polo Cerâmico de Santa Gertrudes” visando informações sobre as características geoquímicas das mesmas.

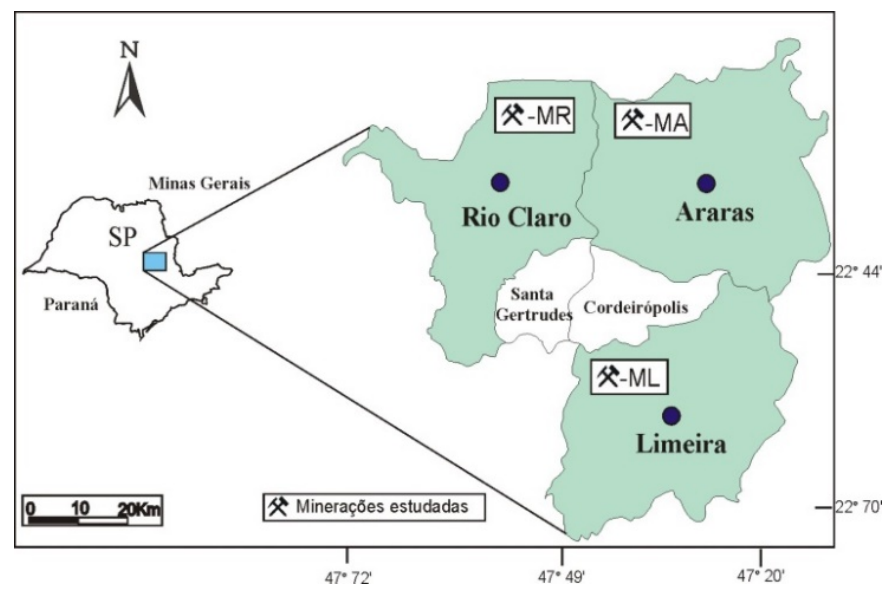

Figura 1 - Mapa de localização dos municípios e das minerações estudadas. SP (Estado de São Paulo), ML (Mineração Limeira), MR (Mineração Rio Claro) e MA (Mineração Araras).

Nos trabalhos de campo, foi possível observar que as três minerações apresentaram cores variadas: cinza/cinza esverdeado normalmente na base (ML: 71, 146; MR: 119; MA: 106), arroxeado/avermelhado dominando nos estratos intermediários e topo (ML: 98, 97, 73, 99; MA: 122, 92; MA: 70, 109, 110), cores avermelhadas nas camadas de solo (ML: 150 e 153) e também na transição rocha/solo (ML:149). Na base das minerações dominam fácies com estrutura maciça e granulometria mais fina. Em direção ao topo das minerações ocorre o aumento da quantidade de areia passando a predominar fácies laminadas, intercaladas siltito/arenito, arenosas, entre outras, as quais são descritas em detalhe por Christofoletti (2006). A Tabela 1 apresenta a análise química dos elementos maiores das três minerações estudadas, incluindo a perda ao fogo (PF), uma vez que está relacionada ao conteúdo de carbonatos e à liberação de água a partir das hidroxilas dos argilominerais e minerais hidratados que não perderam completamente o conteúdo de água durante a secagem a $100^{\circ} \mathrm{C}$. 
Tabela 1 - Análise química dos elementos maiores em \% de óxidos, obtida por Fluorescência de raios X, para amostras de três minerações da Formação Corumbataí designadas como ML (Mineração Limeira), MR (Mineração Rio Claro) e MA (Mineração Araras). Em negrito, as amostras com $\mathrm{CaO}$ maior que $1 \%$.

\begin{tabular}{|c|c|c|c|c|c|c|c|c|c|c|c|}
\hline Am. & $\mathrm{SiO}_{2}$ & $\mathbf{A l}_{2} \mathbf{O}_{3}$ & $\mathrm{Fe}_{2} \mathrm{O}_{3}$ & $\mathrm{TiO}_{2}$ & MnO & $\mathrm{CaO}$ & MgO & $\mathrm{Na}_{2} \mathrm{O}$ & $\mathbf{K}_{2} \mathbf{O}$ & $\mathbf{P}_{2} \mathbf{O}_{5}$ & P.F. \\
\hline \multicolumn{12}{|c|}{ Mineração Limeira-ML } \\
\hline 71 & 67,16 & 14,70 & 4,97 & 0,63 & 0,04 & 0,44 & 2,85 & 2,96 & 3,13 & 0,12 & 2,99 \\
\hline 72 & 70,08 & 14,13 & 3,75 & 0,57 & 0,17 & 0,45 & 2,31 & 2,49 & 2,15 & 0,10 & 3,63 \\
\hline 73 & 68,37 & 13,66 & 6,23 & 0,62 & 0,04 & 0,40 & 2,43 & 2,70 & 2,89 & 0,10 & 2,58 \\
\hline 74 & 65,80 & 14,46 & 6,00 & 0,64 & 0,04 & 0,71 & 2,67 & 3,14 & 3,27 & 0,12 & 3,14 \\
\hline 75 & 66,06 & 13,42 & 4,58 & 0,61 & 0,11 & 1,65 & 3,51 & 3,50 & 2,64 & 0,13 & 3,79 \\
\hline 76 & 62,22 & 13,57 & 5,02 & 0,61 & 0,09 & 2,92 & 3,60 & 3,46 & 2,78 & 0,24 & 5,49 \\
\hline 77 & 63,89 & 13,89 & 4,73 & 0,62 & 0,07 & 2,13 & 3,48 & 3,40 & 3,01 & 0,12 & 4,68 \\
\hline 78 & 59,95 & 12,21 & 3,93 & 0,53 & 0,14 & 4,96 & 4,33 & 3,77 & 2,12 & 0,14 & 7,91 \\
\hline 79 & 67,83 & 14,37 & 5,15 & 0,63 & 0,04 & 0,40 & 2,86 & 2,76 & 3,15 & 0,11 & 2,73 \\
\hline 80 & 32,18 & 9,79 & 32,91 & 0,41 & 0,27 & 1,85 & 14,1 & 0,60 & 0,69 & 0,36 & 6,84 \\
\hline 81 & 67,80 & 13,88 & 5,45 & 0,61 & 0,04 & 0,40 & 2,97 & 2,22 & 3,14 & 0,10 & 3,39 \\
\hline 97 & 65,64 & 14,15 & 5,38 & 0,61 & 0,04 & 0,69 & 2,74 & 2,93 & 3,02 & 0,03 & 4,67 \\
\hline 98 & 62,80 & 13,69 & 4,49 & 0,54 & 0,08 & 2,13 & 3,30 & 3,44 & 2,61 & 0,11 & 6,80 \\
\hline 99 & 63,76 & 12,70 & 3,60 & 0,53 & 0,10 & 4,49 & 4,00 & 4,12 & 1,84 & 0,17 & 4,69 \\
\hline 140 & 68,22 & 14,16 & 5,19 & 0,63 & 0,03 & 0,45 & 2,50 & 2,92 & 2,99 & 0,16 & 2,73 \\
\hline 141 & 66,72 & 14,70 & 5,22 & 0,62 & 0,04 & 0,50 & 2,78 & 3,26 & 3,03 & 0,16 & 2,97 \\
\hline 142 & 61,84 & 12,33 & 3,59 & 0,52 & 0,12 & 4,23 & 4,16 & 4,20 & 1,74 & 0,16 & 7,11 \\
\hline 143 & 68,44 & 14,16 & 4,82 & 0,59 & 0,03 & 0,51 & 2,51 & 2,82 & 2,78 & 0,19 & 3,14 \\
\hline 144 & 69,31 & 13,03 & 4,89 & 0,55 & 0,03 & 0,54 & 3,13 & 2,47 & 2,77 & 0,13 & 3,16 \\
\hline 145 & 68,80 & 14,14 & 4,62 & 0,59 & 0,03 & 0,68 & 2,10 & 2,40 & 2,77 & 0,36 & 3,52 \\
\hline 146 & 67,58 & 14,44 & 4,74 & 0,59 & 0,03 & 0,47 & 2,43 & 5,57 & 2,97 & 0,13 & 4,05 \\
\hline 147 & 68,25 & 15,04 & 4,97 & 0,58 & 0,03 & 0,39 & 2,04 & 1,58 & 3,04 & 0,15 & 3,91 \\
\hline 148 & 67,42 & 15,87 & 5,15 & 0,60 & 0,02 & 0,22 & 2,15 & 1,11 & 3,05 & 0,04 & 4,87 \\
\hline 149 & 55,83 & 21,81 & 9,01 & 1,62 & 0,02 & 0,03 & 0,80 & 0,10 & 1,05 & 0,06 & 9,68 \\
\hline 150 & 40,78 & 27,78 & 16,65 & 3,15 & 0,05 & 0,03 & 0,30 & 0,01 & 0,22 & 0,08 & 10,97 \\
\hline 151 & 65,32 & 16,95 & 5,48 & 0,64 & 0,04 & 0,12 & 2,05 & 0,17 & 2,85 & 0,04 & 6,35 \\
\hline 152 & 61,54 & 20,27 & 7,17 & 0,87 & 0,02 & 0,01 & 1,33 & 0,06 & 2,17 & 0,03 & 6,52 \\
\hline 153 & 39,06 & 28,24 & 17,03 & 3,02 & 0,04 & 0,08 & 0,43 & 0,02 & 0,36 & 0,09 & 11,62 \\
\hline 154 & 66,47 & 16,10 & 6,02 & 0,63 & 0,02 & 0,03 & 1,81 & 0,10 & 2,33 & 0,08 & 6,38 \\
\hline 155 & 63,93 & 15,93 & 4,98 & 0,60 & 0,01 & 0,19 & 1,87 & 3,31 & 3,27 & 0,07 & 5,84 \\
\hline 156 & 72,60 & 10,79 & 4,67 & 0,50 & 0,03 & 0,61 & 2,90 & 2,26 & 2,30 & 0,36 & 3,00 \\
\hline 157 & 70,42 & 12,24 & 5,12 & 0,59 & 0,03 & 0,39 & 3,46 & 2,41 & 2,45 & 0,19 & 2,72 \\
\hline \multicolumn{12}{|c|}{ Mineração Rio Claro-MR } \\
\hline 91 & 64,93 & 18,13 & 4,93 & 0,71 & 0,06 & 0,08 & 2,26 & 0,15 & 2,60 & 0,08 & 6,06 \\
\hline 92 & 62,23 & 18,37 & 4,60 & 0,58 & 0,03 & 0,13 & 2,43 & 0,45 & 3,31 & 0,13 & 7,74 \\
\hline 93 & 62,66 & 10,72 & 4,07 & 0,44 & 0,06 & 7,66 & 4,75 & 3,05 & 1,57 & 0,24 & 4,78 \\
\hline 95 & 65,86 & 12,41 & 4,67 & 0,55 & 0,07 & 2,50 & 5,35 & 2,34 & 2,77 & 0,13 & 3,35 \\
\hline 117 & 68,27 & 12,08 & 3,96 & 0,48 & 0,03 & 1,31 & 4,58 & 2,62 & 2,12 & 0,16 & 4,39 \\
\hline 118 & 66,07 & 11,46 & 4,07 & 0,46 & 0,05 & 3,14 & 4,50 & 2,22 & 2,26 & 0,15 & 5,61 \\
\hline 119 & 69,09 & 12,43 & 2,14 & 0,57 & 0,04 & 1,36 & 4,88 & 1,77 & 3,20 & 0,13 & 4,39 \\
\hline 120 & 66,55 & 12,04 & 3,99 & 0,49 & 0,06 & 2,38 & 4,63 & 2,45 & 2,27 & 0,22 & 4,93 \\
\hline 121 & 61,86 & 10,74 & 3,38 & 0,43 & 0,06 & 5,59 & 5,79 & 2,88 & 1,73 & 0,12 & 7,43 \\
\hline 122 & 56,11 & 10,15 & 3,24 & 0,43 & 0,10 & 10,43 & 4,25 & 2,29 & 1,88 & 0,13 & 10,98 \\
\hline 123 & 63,87 & 16,61 & 5,32 & 0,64 & 0,03 & 0,09 & 2,03 & 0,08 & 1,70 & 0,14 & 9,50 \\
\hline \multicolumn{12}{|c|}{ Mineração Araras-MA } \\
\hline 67 & 61,22 & 20,35 & 5,61 & 0,83 & 0,10 & 1,19 & 1,76 & 1,03 & 2,99 & 0,04 & 5,90 \\
\hline 68 & 59,69 & 12,85 & 4,31 & 0,58 & 0,14 & 6,87 & 2,04 & 3,69 & 2,55 & 0,17 & 7,12 \\
\hline 69 & 68,31 & 13,18 & 4,54 & 0,57 & 0,04 & 1,42 & 2,84 & 2,02 & 2,49 & 0,32 & 4,25 \\
\hline 70 & 73,16 & 12,14 & 3,94 & 0,51 & 0,09 & 0,64 & 1,90 & 2,08 & 2,34 & 0,11 & 3,08 \\
\hline 106 & 69,81 & 12,00 & 3,10 & 0,47 & 0,07 & 3,05 & 1,47 & 3,94 & 1,80 & 0,19 & 4,09 \\
\hline 107 & 55,66 & 9,23 & 2,98 & 0,34 & 0,11 & 13,88 & 1,70 & 1,92 & 1,41 & 0,26 & 12,50 \\
\hline 108 & 72,47 & 11,88 & 3,19 & 0,42 & 0,08 & 1,39 & 2,24 & 1,99 & 1,98 & 0,54 & 3,82 \\
\hline 109 & 67,63 & 14,40 & 4,85 & 0,58 & 0,04 & 0,61 & 2,89 & 1,34 & 3,00 & 0,09 & 4,57 \\
\hline 110 & 70,00 & 12,86 & 5,05 & 0,55 & 0,07 & 0,23 & 2,78 & 1,08 & 3,57 & 0,08 & 3,74 \\
\hline 111 & 66,48 & 11,45 & 3,79 & 0,46 & 0,08 & 2,48 & 5,35 & 2,05 & 2,36 & 0,22 & 5,29 \\
\hline
\end{tabular}


Realizou-se a comparação do conteúdo relativo de cátions entre as amostras das três minerações, representado pela soma da proporção catiônica (Rollinson, 1995). Essa comparação fornece informações sobre o estado de alteração intempérica, amostras mais alteradas contêm menores valores e sua localização normalmente ocorre nas porções superiores das minerações.

Na figura 2 estão representados os valores, individualmente, para as três minerações (ML, MR e MA).

Na figura 3, seguindo uma ordem crescente, para todas as amostras, pode se observar duas sequências de pontos bem diferenciadas, à esquerda da figura 3 se localizam as amostras com maior exposição aos agentes intempéricos, enquanto as demais amostras, mais numerosas, apresentam o valor da soma da proporção catiônica em torno de 1,69.

Quando se comparam as três minerações na zona de maior concentração de amostras (Figura 3) pode ser notada uma diferença do valor médio da proporção catiônica da mineração MA em relação às minerações $M L$ e MR o que pode indicar que estas foram mais expostas a agentes intempéricos.

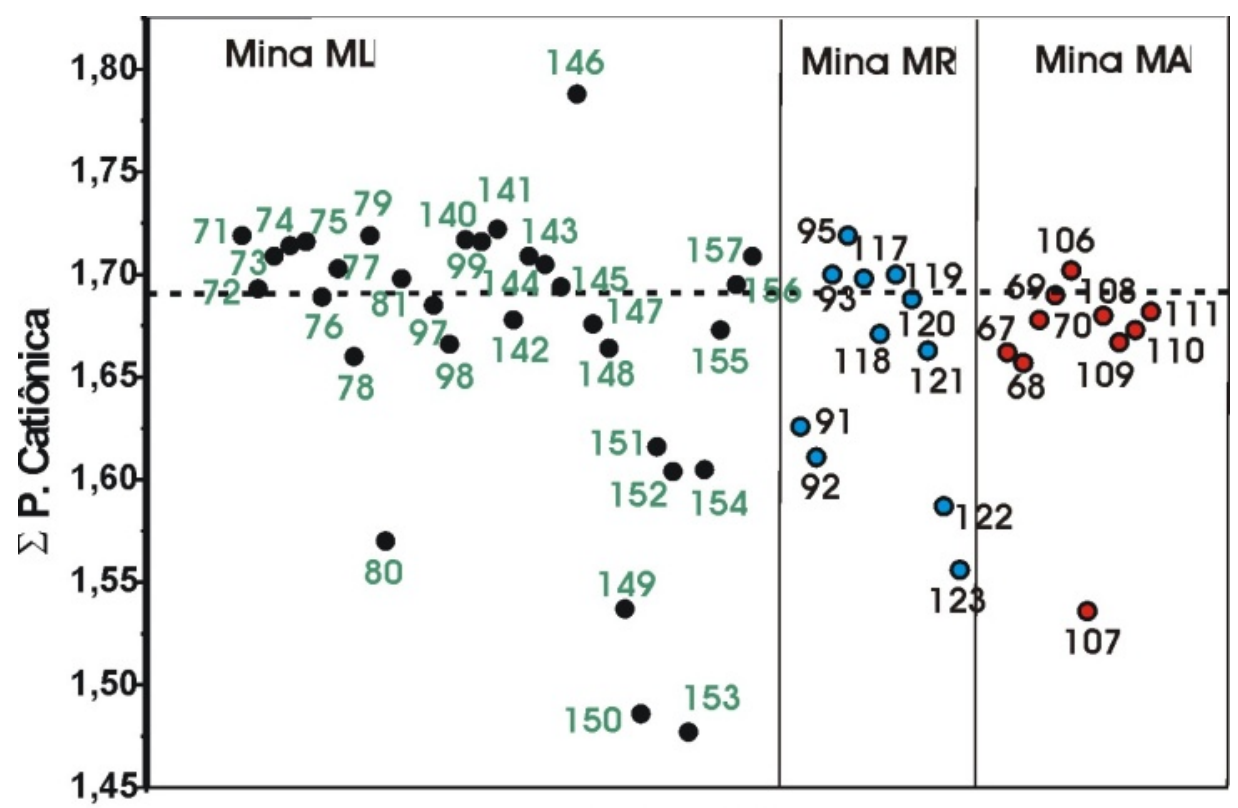

AMOSTRAS

Figura 2 - Representação do conteúdo de cátions através da soma da proporção catiônica dos elementos maiores para as amostras das minerações ML (Limeira), MR (Rio Claro) e MA (Araras).

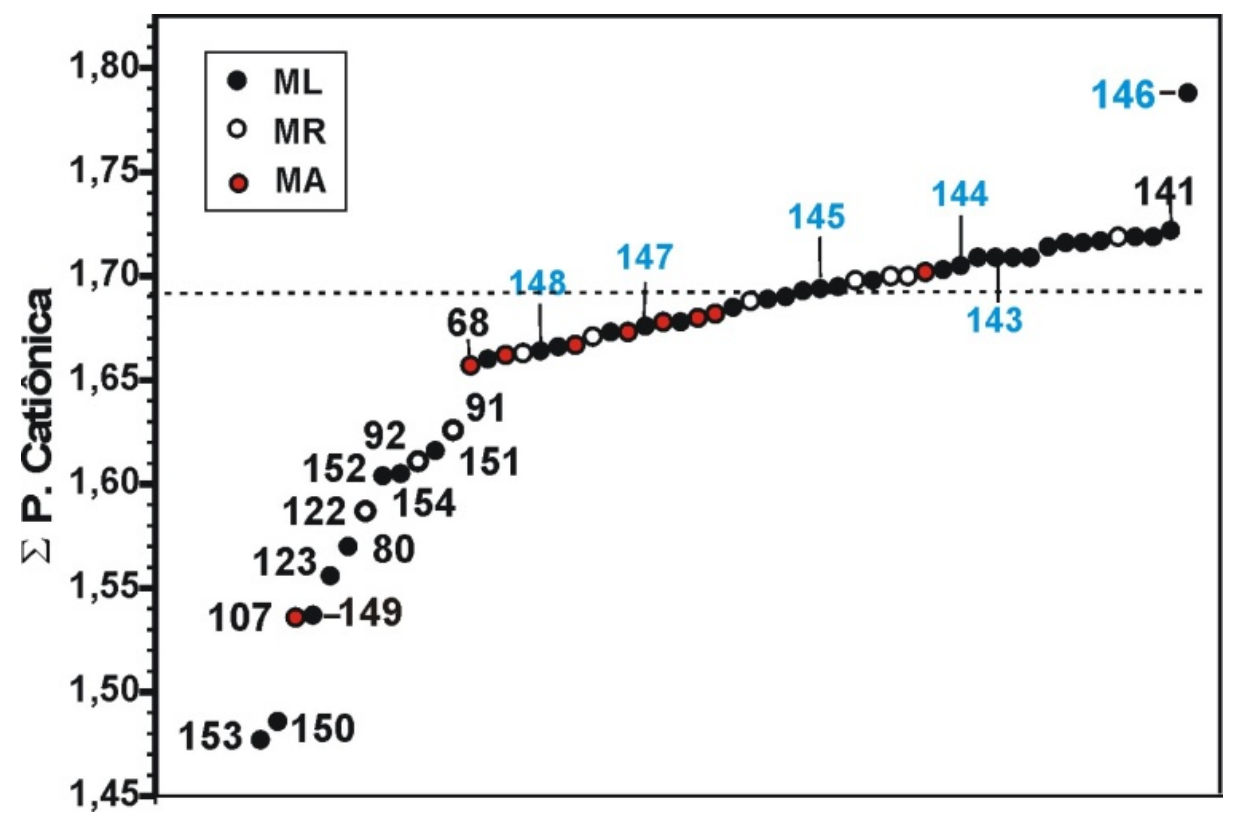

Figura 3 - Representação do conteúdo relativo de cátions através da soma da proporção catiônica para o conjunto de amostras das três minerações (ML, MR e MA), em ordem crescente. As amostras identificadas na sequência à direita correspondem a siltitos da mineração ML. 
As características apresentadas pelas amostras nas descrições de campo justificam a distribuição apresentada nas figuras 2 e 3, principalmente as mais alteradas.

As amostras 150 e 153 representam níveis de solos; a amostra 80 com alto conteúdo de ferro depositado por efeitos de lixiviação; as amostras 92, 151, 152 e 154 apresentam elevado conteúdo de alumínio; 123 é uma amostra da porção superior (topo); 122 e 107 contém altos valores de carbonato; 91 é um siltito arenoso que permite percolação de fluídos e a 149 siltito com alto conteúdo de ferro e alumínio, concentrados por efeitos de lixiviação de outros elementos mais móveis como cálcio e sódio (Tabela 1).

Por outro lado, a amostra 146 apresentou maior conteúdo total de cátions pela elevada presença de $\mathrm{Na}_{2} \mathrm{O}$, da ordem de $5,57 \%$, indicando alto conteúdo do mineral albita e alteração intempérica baixa preservada por sua textura fina, maciça e localização na base da Formação Corumbataí, acima do contato que esta faz com a Formação Irati (Moreno et al., 2012).

Na figura 3 observa se uma linha traçada em torno do valor 1,69 da soma da proporção catiônica, possivelmente uma característica geral das argilas menos alteradas na região estudada (Moreno et al., 2016). Na figura 4 é possível observar um conjunto de siltitos coletados em diferentes pontos da mineração ML e que contém valores de $\mathrm{CaO}$ inferiores a 1\% (amostras $\mathrm{ML}$ 143 a ML 149) (Figura 3).

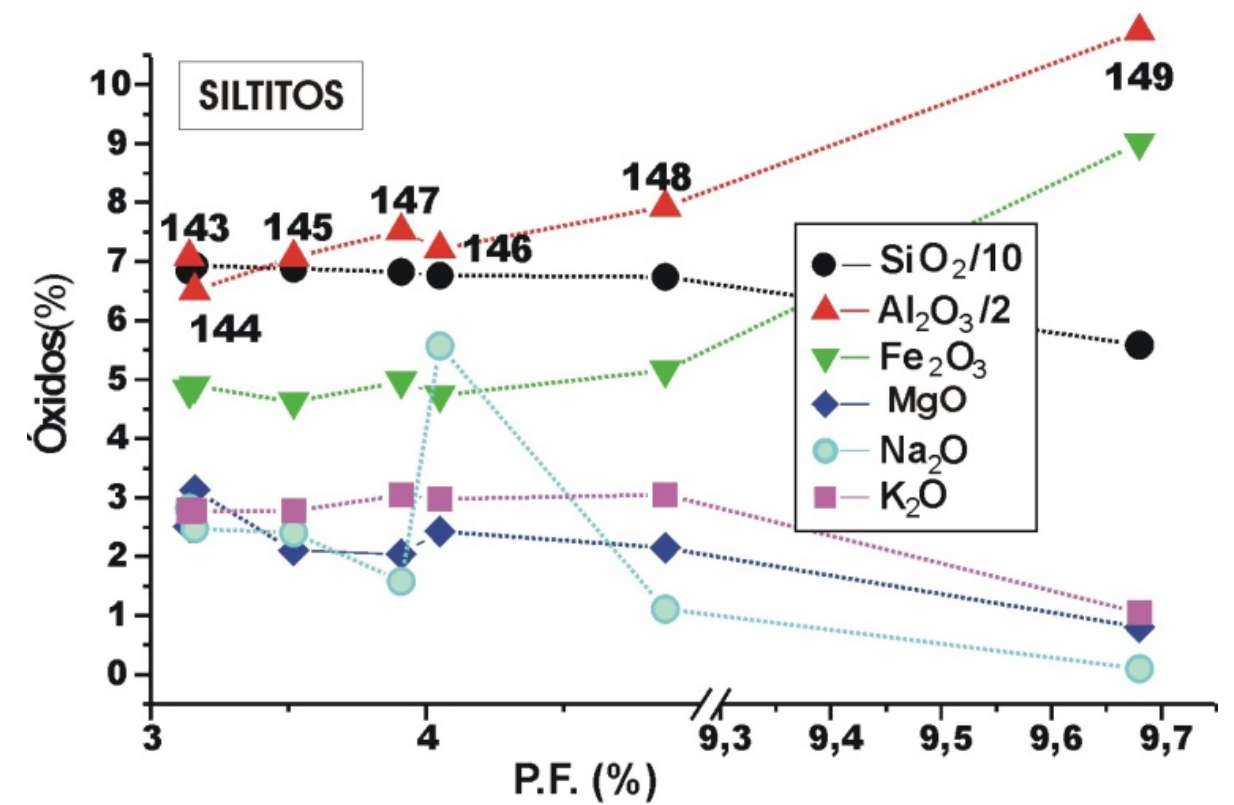

Figura 4 - Gráfico da variação da concentração dos principais elementos em função da perda ao fogo para siltitos da mineração ML com teor de $\mathrm{CaO}$ menor que 1\%. Estas amostras foram identificadas na Figura 3.

As amostras 143 (arroxeado) e 144 (cinza esverdeado) apresentam valores de perda ao fogo similar com diferença na coloração devida ao estado de oxidação do ferro, reduzido na amostra 144, uma vez que não foi identificada hematita na difração de raios $\mathrm{X}$.

Esta alteração possivelmente está ligada à percolação de fluídos quentes decorrentes de processo de hidrotermalismo (Costa, 2016).

As amostras 145, 146, 147 e 148 apresentaram valores diferentes de Perda ao Fogo (PF), sendo maior na amostra 148 pela maior concentração de $\mathrm{Al}_{2} \mathrm{O}_{3}$ e menor de $\mathrm{Na}_{2} \mathrm{O}$ (Tabela 1), indicando maior alteração conforme soma da proporção catiônica na figura 3.

A amostra 146 apresenta valor de PF próximo da amostra 147, porém com maior conteúdo de sódio contido no feldspato sódico, mineral que não contribui para o aumento dos valores de PF (Figura 3).

Já a amostra 148 apresenta PF em torno de $1 \%$ maior que as amostras 146 e 147, o que é devido à maior quantidade de alumínio (15,82\% de $\left.\mathrm{Al}_{2} \mathrm{O}_{3}\right)$ e ferro $\left(5,15 \%\right.$ de $\left.\mathrm{Fe}_{2} \mathrm{O}_{3}\right)$ concentrados por efeitos de lixiviação mais acentuados, indicando maior quantidade de minerais hidratados.

A amostra 149 apresenta maiores valores de PF decorrente da maior concentração $\mathrm{Al}_{2} \mathrm{O}_{3}$ e $\mathrm{Fe}_{2} \mathrm{O}_{3}$ causada por alta lixiviação dos íons $\mathrm{Si}^{4+}$, $\mathrm{Mg}^{2+}, \mathrm{Na}^{+}$e $\mathrm{K}^{+}$(Tabela 1). A relação da perda ao fogo (PF) com o teor de $\mathrm{CaO}$ pode ser observada no gráfico da figura 5 onde valores de $\mathrm{CaO}$ menores que $1 \%$ correspondem a $\mathrm{PF}$ 
resultante basicamente da $\mathrm{H}_{2} \mathrm{O}$ formada a partir da decomposição dos argilominerais, uma vez que foi constatado que o conteúdo de componentes passíveis de decomposição, tais como matéria orgânica, sulfatos e piritas é baixo ou nulo. Amostras que contém $\mathrm{CaO}$ acima de $1 \%$ tem como causa dominante perdas de $\mathrm{H}_{2} \mathrm{O}$ e de $\mathrm{CO}_{2}$ dos carbonatos, observando se para o conjunto de amostras uma tendência de aumento de PF com o aumento do $\mathrm{CaO}$.

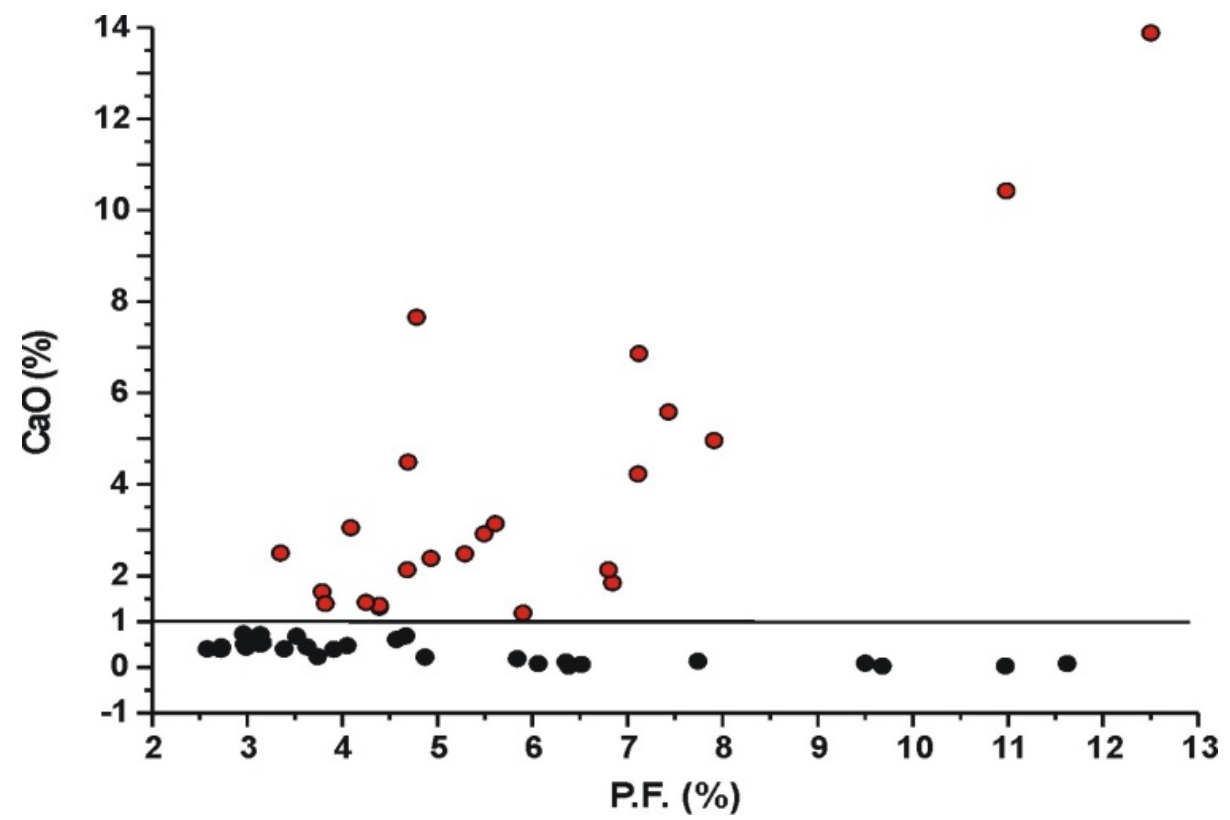

Figura 5 - Separação das amostras em dois grupos em função do conteúdo de CaO.

A partir das observações realizadas, as amostras foram analisadas em dois grupos: GA com valores superiores a $1 \%$ de $\mathrm{CaO}$ e GB com valores inferiores a $1 \%$ de $\mathrm{CaO}$. É possível observar alinhamento de pontos em ambos os grupos, alguns com aproximadamente o mesmo valor de perda ao fogo (P.F) e outros com aumento ou diminuição deste parâmetro em função do teor de $\mathrm{CaO}$, indicando relação entre as amostras conforme linhas traçadas nas figuras 6 e 7 .
Nas amostras GA ( $\mathrm{CaO}>1 \%)$, da figura 6, foram marcadas duas sequências de pontos (SI) e (S-II) aproximadamente paralelas significando variação regular de $\mathrm{CaO}$ com $\mathrm{PF}$, onde a sequência (S-II) tem seu início em uma concentração menor de $\mathrm{CaO}$. O conjunto de amostras 77, 99 e 93 e o conjunto 98, 80, 142 e 68 (linhas pontilhadas) apresentam PF quase constante apesar do aumento de $\mathrm{CaO}$ devido à redução na quantidade de água liberada pelas amostras.

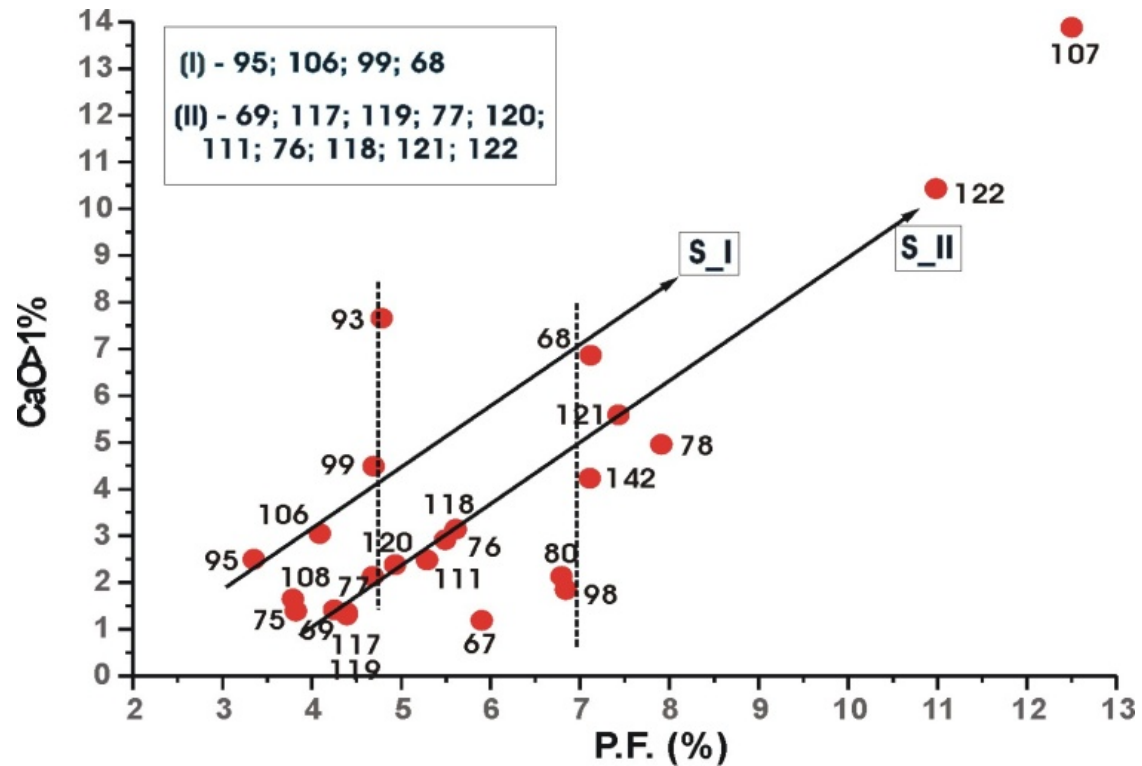

Figura 6 - Relação da perda ao fogo com teores de $\mathrm{CaO}$ maior que 1\% (Grupo GA) mostrando alinhamento de pontos. 
Para o grupo GB $(\mathrm{CaO}<1 \%)$ (Figura 7) foram traçados três alinhamentos com características diferentes para as variáveis relacionadas: sequência (S-III) onde PF é aproximadamente constante; sequência (S-IV), de variação positiva com P.F em intervalo menor que $2 \%$; sequência (S-V), com variação inversa de $\mathrm{CaO}$ dentro de uma extensa faixa de PF (maior que 7\%).

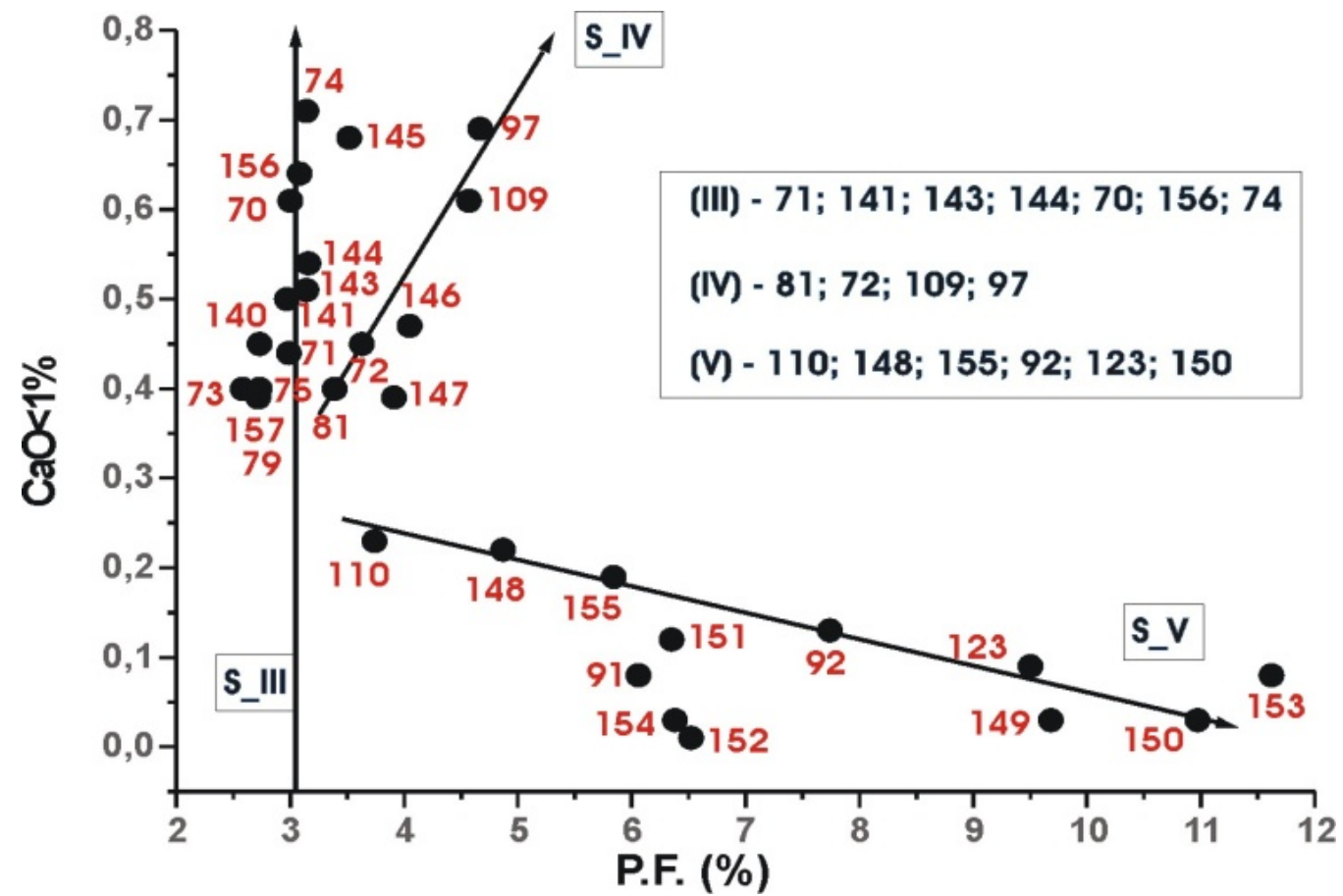

Figura 7 - Relação da perda ao fogo com teores de $\mathrm{CaO}$ menores que 1\% (Grupo GB) mostrando alinhamento de pontos.

As amostras do Grupo GA têm como causa dominante a variação (ou não) de PF pela decomposição de carbonatos e/ou dos argilominerais. Os gráficos da figura 8 mostram os diagramas de variação dos elementos indicativos destes compostos $\left(\mathrm{CaO}, \mathrm{SiO}_{2}\right.$ e $\mathrm{Al}_{2} \mathrm{O}_{3}$ ) em função de $\mathrm{PF}$.

Ao comparar os gráficos A (S-I) e B (S-II) da figura $8(\mathrm{CaO}>1 \%)$, observa-se que a sequência (S-II) tem maior variação de $\mathrm{CaO}$ e de perda ao fogo (PF), além de variação inversa tanto para $\mathrm{Al}_{2} \mathrm{O}_{3}$ como para $\mathrm{SiO}_{2}$ cujas inclinações são paralelas indicando conteúdo regular destes óxidos, sendo o $\mathrm{CO}_{2}$ a causa principal da variação da $\mathrm{PF}$ e $\mathrm{H}_{2} \mathrm{O}$ aproximadamente constante.

A sequência (S-I) (Figura 8A) mostra diferente inclinação das retas $\mathrm{Al}_{2} \mathrm{O}_{3}$ e $\mathrm{SiO}_{2}$, mantendo $\mathrm{Al}_{2} \mathrm{O}_{3}$ aumento positivo com $\mathrm{PF}$, da mesma forma que $\mathrm{CaO}$, indicando influência maior de $\mathrm{H}_{2} \mathrm{O}$ em PF do que na sequência (SII). Na figura $8 \mathrm{~F}$ pode ser observado que a variação $\mathrm{SiO}_{2} / \mathrm{Al}_{2} \mathrm{O}_{3}$ das sequências (S-I e S-II) é pequena comparada com a (S-III e S-V) devido à presença, nas primeiras sequências, de $\mathrm{CaO}$ dos carbonatos. No caso das amostras com PF aproximadamente constante, (77, 99 e 93) e (98, 80, 142 e 68), ocorre uma compensação, ou seja, para menor $\mathrm{CaO}$ há maior quantidade de $\mathrm{H}_{2} \mathrm{O}$ liberada, de tal forma que $\mathrm{PF}$ não tem modificação significativa.

Para as amostras do Grupo GB a figura 8C (S-III) apresenta separação dos pontos em duas subsequências: (141, 71, 143 e 74) e (156, 70 e 144). A primeira apresenta pouca variação de $\mathrm{Al}_{2} \mathrm{O}_{3}$ com $\mathrm{PF}$ e a segunda um aumento crescente de $\mathrm{Al}_{2} \mathrm{O}_{3}$ com $\mathrm{PF}$, refletindo uma diferenciação entre os tipos/quantidades de argilominerais conforme difração de raios $\mathrm{X}$ (DRX) (Tabela 2, sequência S-III), havendo menor concentração de illita devido à alteração para vermiculita e clorita.

A sequência (S-IV), figura $8 \mathrm{D}$, não apresenta variação de $\mathrm{Al}_{2} \mathrm{O}_{3}$ e $\mathrm{SiO}_{2}$ entre as amostras na faixa de aumento de PF de (1,3\%) configurando maior semelhança entre elas. $\mathrm{Na}$ figura $8 \mathrm{~F}$ pode ser observada a pequena variação de $\mathrm{SiO}_{2} / \mathrm{Al}_{2} \mathrm{O}_{3}$ da amostra 109 para a 72. A DRX (Tabela 2) demonstra evolução para clorita e estruturas estratificadas irregulares.

A sequência $\mathrm{S}-\mathrm{V}$ (gráfico da figura 8E) ocorre dentro de uma ampla faixa de variação de perda ao fogo $(7,4 \%)$ com queda da sílica e aumento de $\mathrm{Al}_{2} \mathrm{O}_{3}$ em uma proporção de 5 unidades na relação $\mathrm{SiO}_{2} / \mathrm{Al}_{2} \mathrm{O}_{3}$, resultado de alteração para argilominerais do grupo da 
caulinita $\left[\mathrm{Al}_{2} \mathrm{Si}_{2} \mathrm{O}_{5}(\mathrm{OH})_{4}\right]$ em proporções variadas. A DRX (Tabela 2) indica que esta alteração passa por clorita e esmectita. A amostra 150 é a mais alterada (Tabela 2) por estar localizada próxima à camada de solo, local onde a illita já foi transformada por efeitos de lixiviação (Figura 8E, S-V).

$\mathrm{Na}$ figura 8F observa se um declínio da relação $\mathrm{SiO}_{2} / \mathrm{Al}_{2} \mathrm{O}_{3}$ com $\mathrm{PF}$, inclusive para as
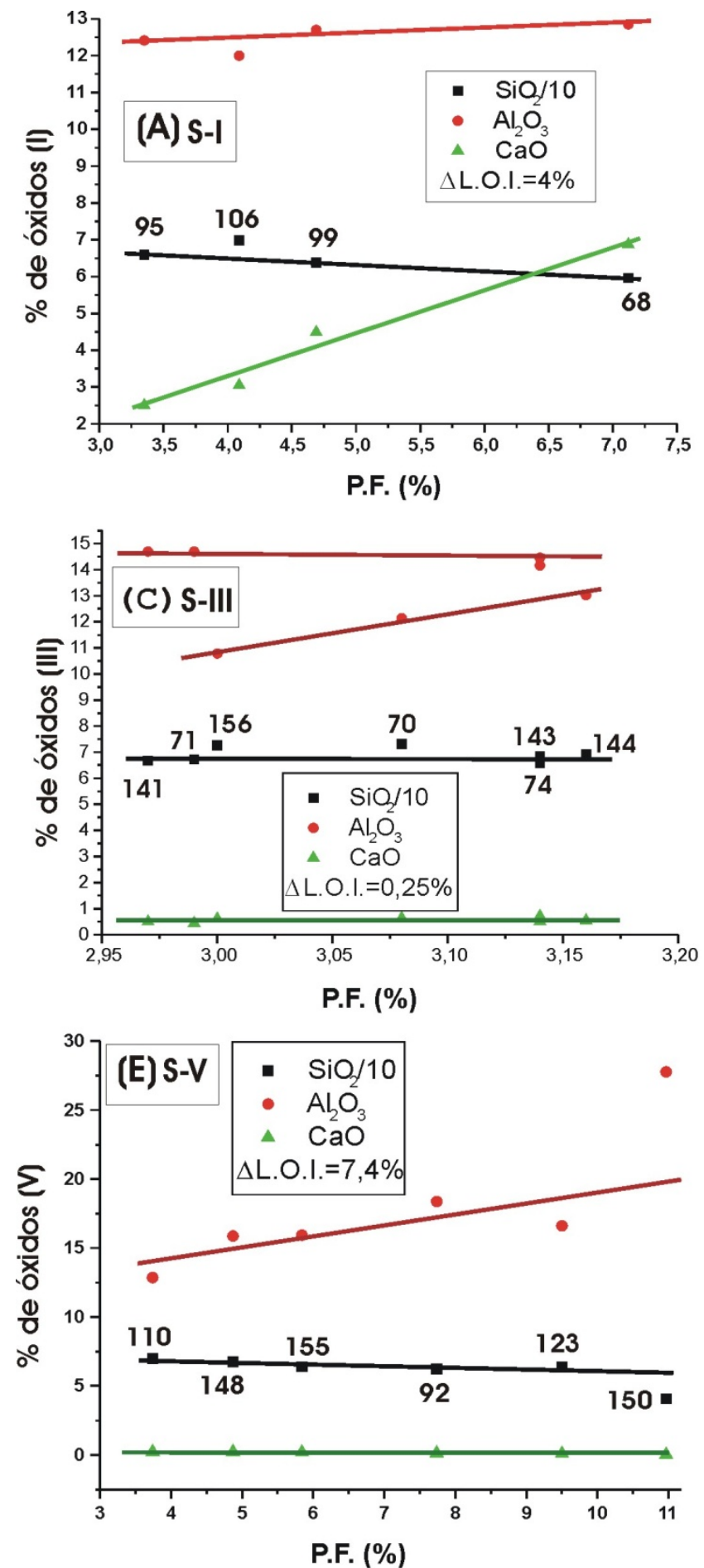

sequências ( $\mathrm{S}-\mathrm{I}$ e S-II), a qual resulta de um aumento de $\mathrm{Al}_{2} \mathrm{O}_{3}$ ou diminuição de $\mathrm{SiO}_{2}$ decorrente da variação do tipo e proporção de argilominerais/hidróxidos, assim como do conteúdo de carbonatos. Determinados pontos das sequências (S-I, S-II e S-V) estão deslocados do alinhamento devido à maior e/ou menor concentração de quartzo e feldspatos, os quais não liberam água durante o aquecimento.
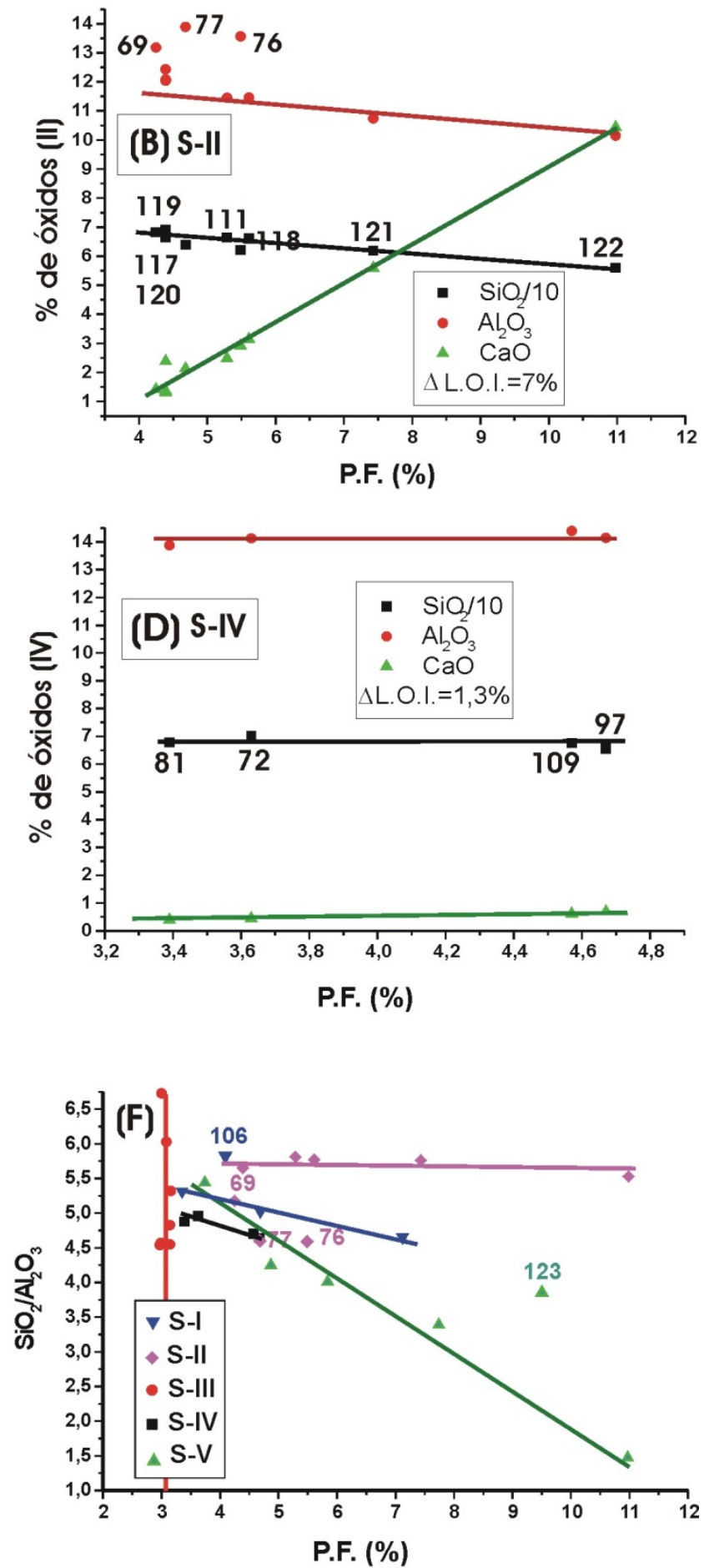

Figura 8 - Relação dos óxidos de Ca, Al e Si com a perda ao fogo (PF): (A) e (B) para as sequências (S-I e S-II) que correspondem a teores de $\mathrm{CaO}>1 \%$ e (C), (D), (E) para as sequências (S-III, S-IV e S-V) com teores de CaO < 1\%, e, (F) relação $\mathrm{SiO}_{2} / \mathrm{Al}_{2} \mathrm{O}_{3}$ e PF para as amostras das sequências (S-I, S-II, S-III, S-IV e S-V). 
Para as amostras que ficaram fora das sequências (S-I, S-II, S-III, S-IV e S-V) há a presença de minerais que não liberam gases, no entanto, contém os mesmos elementos, porém, com variação das concentrações que posicionam as amostras em outras coordenadas (Figura 9). Os parâmetros são indicativos do grau relativo de alteração das amostras, evidenciando a tendência do conjunto à formação de fórmulas químicas mais simples, causada pela perda dos elementos mais móveis e pela concentração de outros, tais como o alumínio, titânio ou ferro.

A tendência de queda de $\mathrm{SiO}_{2}$ é mostrada pelas duas variáveis, e ocorre como resultado da transformação dos feldspatos em argilominerais e de illitas em outros argilominerais. $\mathrm{O}$ alinhamento de pontos é mais bem definido pela soma da proporção catiônica.

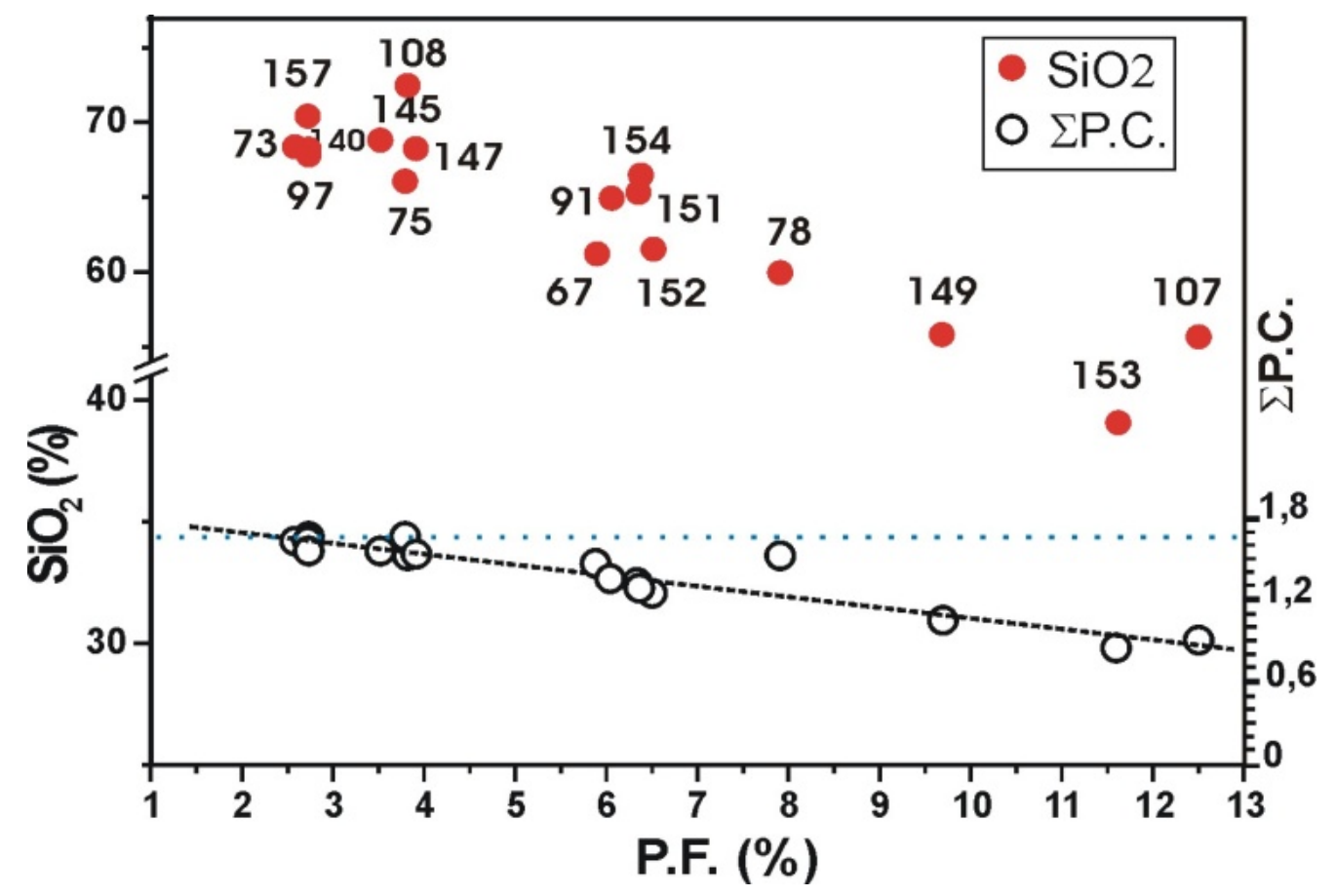

Figura 9 - Variação da perda ao fogo (PF) com o conteúdo de sílica e de cátions das amostras não incluídas nas sequências (S-I, S-II, S-III, S-IV e S-V). O conteúdo de cátions é representado pela soma da proporção catiônica (SPC) ou número relativo de elementos positivos entre as amostras.

A mineralogia principal das sequências (S-I a S-V) foi obtida a partir dos gráficos de difração de raios X (Tabela 2). Em todas as amostras foi identificado o mineral quartzo. O feldspato albita ocorreu em todas as sequências exceção para S-V.

Em relação aos argilominerais, a illita representa o principal argilomineral, só não ocorre na amostra 150. A caulinita é o argilomineral predominante na sequência (S-V) associada a estratificações irregulares e está composto por amostras mais alteradas pela ação do intemperismo.

Nas sequencias S-I e S-II, amostras com teor de $\mathrm{CaO}>1 \%$, contém illita, cloritas e esmectitas (relação Si:Al::2:1), exceto as amostras 99 (S-I) e 111 (S-II) com ausência de clorita e presença de dolomita o que aumenta a perda ao fogo, e valores de SPC conforme a figura 2 (SPC $\geq 1,69)$.

As amostras da sequência (S-III) apresentam baixa concentração de minerais expansivos e estratificações irregulares com valores de SPC maiores que 1,69, exceto na amostra 70 que possui vermiculita. Em S-IV não foram observadas esmectitas, somente cloritas e estratificações irregulares com leve expansão, illita com estagio de alteração maior que em S-III (SPC < 1,69).

Na sequência (S-V) prevalecem caulinitas (relação Si:Al::1:1) acompanhadas de estratificações irregulares com SPC menores que S-IV.

A contribuição de illitas é variável e sua transformação pode ser avaliada observando o conjunto de argilominerais da tabela 2.

As amostras não carbonáticas possuem uma alteração crescente, nas sequências S-III a S-V, amostras associadas a cloritas em S-III e S-IV, com maior conteúdo de estruturas estratificadas irregulares em S-IV, e associadas a caulinitas na sequência $S-V$.

A moagem a seco utilizada na indústria cerâmica de revestimentos, mais precisamente, no polo cerâmico localizado na região de estudo, 
Tabela 2 - Estimativa do conteúdo relativo de minerais a partir dos gráficos de difração de raios X, tendo como base a altura do pico principal ou aquele com menos interferências. Cal=calcita; Dol=dolomita; $\mathrm{Ill=illita;} \mathrm{Sm}=$ esmectitas; $\mathrm{Cl}=$ cloritas; $\mathrm{K}=$ caulinita; Vm=vermiculita; E=estratificações irregulares de argilominerais.

\begin{tabular}{|c|c|c|c|c|c|c|c|c|}
\hline Am & Cal & Dol & Ill & $\mathrm{Sm}$ & Cl & $\mathbf{K}$ & Vm & $\mathbf{E}$ \\
\hline \multicolumn{9}{|c|}{ Sequência S-I } \\
\hline 95_ML & $\mathrm{xX}$ & - & $\mathrm{XXX}$ & $\mathrm{xxx}$ & $\mathrm{XXX}$ & - & - & - \\
\hline 106_MA & $\mathrm{XX}$ & - & $\mathrm{x}$ & $\mathrm{XXX}$ & $\mathrm{x}$ & - & - & - \\
\hline 99_ML & $\mathrm{x}$ & $\mathrm{x}$ & $\mathrm{xx}$ & $\mathrm{XXX}$ & - & - & - & - \\
\hline 68_MA & $\mathrm{xxx}$ & - & $\mathrm{xxx}$ & $\mathrm{xx}$ & $\mathrm{x}$ & - & - & $\mathrm{xX}$ \\
\hline \multicolumn{9}{|c|}{ Sequência S-II } \\
\hline 69_MA & $\mathrm{x}$ & - & $\mathrm{XXX}$ & $\mathrm{XX}$ & $\mathrm{XX}$ & - & - & $\mathrm{XX}$ \\
\hline 117_MR & $\mathrm{x}$ & - & $\mathrm{xx}$ & $\mathrm{XXXX}$ & $\mathrm{X}$ & - & - & - \\
\hline 119_MR & $\mathrm{x}$ & - & $\mathrm{XX}$ & $\mathrm{XXXX}$ & $\mathrm{x}$ & - & - & $\mathrm{x}$ \\
\hline 77_ML & $\mathrm{x}$ & $\mathrm{x}$ & $\mathrm{xxx}$ & $\mathrm{xx}$ & $\mathrm{XX}$ & - & - & $\mathrm{XX}$ \\
\hline 120_MR & $\mathrm{xx}$ & $\mathrm{x}$ & $\mathrm{xx}$ & $\mathrm{XXXX}$ & $\mathrm{XX}$ & - & - & $\mathrm{x}$ \\
\hline 111_MA & $\mathrm{x}$ & $\mathrm{xx}$ & $\mathrm{XX}$ & $\mathrm{XXXX}$ & - & - & - & $\mathrm{x}$ \\
\hline 76_ML & $\mathrm{xx}$ & $\mathrm{XXX}$ & $\mathrm{xxx}$ & $\mathrm{XX}$ & $\mathrm{XX}$ & - & - & $\mathrm{XX}$ \\
\hline 118_MR & $\mathrm{XXX}$ & $\mathrm{X}$ & $\mathrm{xx}$ & $\mathrm{XXX}$ & $\mathrm{XXX}$ & - & - & $\mathrm{x}$ \\
\hline 121_MR & $\mathrm{xxx}$ & - & $\mathrm{XX}$ & $\mathrm{xxx}$ & $\mathrm{xxx}$ & - & - & $\mathrm{X}$ \\
\hline 122_MR & $\mathrm{XXXx}$ & - & $\mathrm{XX}$ & $\mathrm{xxx}$ & $\mathrm{XXX}$ & - & - & $\mathrm{x}$ \\
\hline \multicolumn{9}{|c|}{ Sequência S-III } \\
\hline 71_ML & - & - & $\mathrm{xxxx}$ & $\mathrm{X}$ & $\mathrm{XXXx}$ & - & - & $\mathrm{x}$ \\
\hline 141_ML & - & - & $\mathrm{xxx}$ & $\mathrm{x}$ & $\mathrm{x}$ & - & - & $\mathrm{xX}$ \\
\hline 143_ML & - & - & $\mathrm{xxx}$ & - & $\mathrm{XX}$ & - & - & $\mathrm{XX}$ \\
\hline 144_ML & - & - & $\mathrm{xx}$ & - & $\mathrm{XXXX}$ & - & - & $\mathrm{x}$ \\
\hline 70_MA & - & - & $\mathrm{x}$ & - & - & - & $\mathrm{x}$ & $\mathrm{xX}$ \\
\hline 156_ML & - & - & $\mathrm{x}$ & - & $\mathrm{xxX}$ & $\mathrm{x}$ & $\mathrm{XX}$ & $\mathrm{xx}$ \\
\hline 74_ML & - & - & $\mathrm{xxxx}$ & - & $\mathrm{xx}$ & - & - & $\mathrm{xx}$ \\
\hline \multicolumn{9}{|c|}{ Sequência S-IV } \\
\hline 81_ML & - & - & $\mathrm{XX}$ & - & XXXX & - & - & $\mathrm{xX}$ \\
\hline 72_ML & - & - & $\mathrm{XXX}$ & - & $\mathrm{XXXX}$ & - & - & $\mathrm{XX}$ \\
\hline 109_MA & - & - & $\mathrm{XX}$ & - & $\mathrm{x}$ & - & - & $\mathrm{xxX}$ \\
\hline 97_ML & - & - & $\mathrm{XXX}$ & - & $\mathrm{xXX}$ & - & - & $\mathrm{xx}$ \\
\hline \multicolumn{9}{|c|}{ Sequência S-V } \\
\hline 110_MA & - & - & $\mathrm{XX}$ & - & $\mathrm{xx}$ & $\mathrm{x}$ & - & $\mathrm{XX}$ \\
\hline 148_ML & - & - & $\mathrm{xxx}$ & $\mathrm{x}$ & - & $\mathrm{xX}$ & - & $\mathrm{xX}$ \\
\hline 155_ML & - & - & $\mathrm{XXXx}$ & $\mathrm{XX}$ & - & $\mathrm{XX}$ & - & $\mathrm{XX}$ \\
\hline 92_MR & - & - & $\mathrm{xx}$ & - & - & $\mathrm{xxx}$ & - & $\mathrm{XX}$ \\
\hline 123_MR & - & - & $\mathrm{xx}$ & - & $\mathrm{x}$ & $\mathrm{xxx}$ & - & $\mathrm{xx}$ \\
\hline 150_ML & - & - & - & - & - & XXXX & - & $\mathrm{XX}$ \\
\hline
\end{tabular}

permite temperaturas de queima maiores que $1000^{\circ} \mathrm{C}$ onde se processam outras reações.

Estas reações não possuem variação da massa, desta forma, as sequências definidas acima não mostram necessariamente o mesmo comporta-mento, principalmente pela influência do empacotamento das partículas adquirido durante a confecção das peças (Tabela 3) e de elementos fundentes, tais como o sódio da albita e potássio das illitas. Para analisar estes efeitos foi utilizado o teor de $\mathrm{Na}_{2} \mathrm{O}$, presente na maioria das amostras (Tabela 1), o qual demonstra o efeito fundente a temperaturas acima de $1000^{\circ} \mathrm{C}$, além da absorção de água (AA) obtida em peças queimadas a temperaturas de 1070 e $1120^{\circ} \mathrm{C}$ (Tabela 3).
Para analisar a influência do teor de $\mathrm{CaCO}_{3}$ na sinterização das peças cerâmicas, as análises químicas foram normalizadas para 100\% excluindo o conteúdo de $\mathrm{CaO}$ com o objetivo de entender os efeitos da sua decomposição sobre a perda ao fogo. As amostras com teor de $\mathrm{CaO}$ maior que $1,39 \%$ foram divididas em três grupos com variação máxima no teor de $\left[\mathrm{Na}_{2} \mathrm{O}\right]_{\mathrm{N}}$ de aproximadamente $0,5 \%$ para minimizar os efeitos sinterizantes de sódio entre as amostras de cada grupo: Grupos GQ 1 com $\left[\mathrm{Na}_{2} \mathrm{O}\right]_{\mathrm{N}}$ variando de 1,99 a 2,45\% (amostras 95, 108, 69,120, 111,118, 122 e 107); GQ 2 com $\left[\mathrm{Na}_{2} \mathrm{O}\right]_{\mathrm{N}}$ variando de 3,05 a 3,46\% (amostras 75, 77, 93,76, 98 e 121) e GQ 3 com $\left[\mathrm{Na}_{2} \mathrm{O}\right]_{\mathrm{N}}$ variando de 3,96 a 4,43 (amostras 106, 99, 142, 68 e 78). 
Tabela 3 - Caracterização cerâmica das amostras (Up= umidade de prensagem; Dp= densidade de prensagem; AA1 e DQ1, Absorção de água e Densidade Aparente após queima a 1070 C; AA2 e DQ2, Absorção de água e Densidade Aparente após queima a $\left.1120^{\circ} \mathrm{C}\right)$.

\begin{tabular}{|c|c|c|c|c|c|c|}
\hline Amostras & Up (\%) & Dp (g.cm $\left.{ }^{-3}\right)$ & AA1 (\%) & DQ1 (g.cm $\left.{ }^{-3}\right)$ & AA2 (\%) & DQ2 (g.cm $\left.{ }^{-3}\right)$ \\
\hline \multicolumn{7}{|c|}{ Mineração (ML) } \\
\hline 71 & 7,95 & 1,78 & 11,37 & 1,94 & 4,03 & 2,13 \\
\hline 72 & 8,82 & 1,80 & 11,56 & 1,93 & 4,69 & 2,08 \\
\hline 73 & 9,85 & 1,86 & 10,98 & 1,98 & 6,03 & 2,07 \\
\hline 74 & 8,78 & 1,82 & 7,54 & 2,07 & 0,89 & 2,14 \\
\hline 75 & 8,80 & 1,82 & 20,86 & 1,67 & 0,47 & 2,18 \\
\hline 76 & 8,36 & 1,80 & 20,26 & 1,67 & 1,63 & 2,12 \\
\hline 77 & 8,55 & 1,83 & 21,64 & 1,69 & 4,05 & 2,12 \\
\hline 78 & 8,44 & 1,73 & 29,24 & 1,48 & 8,88 & 1,98 \\
\hline 79 & 9,78 & 1,78 & 11,67 & 1,93 & 5,38 & 2,06 \\
\hline 80 & 9,76 & 1,97 & 15,93 & 2,18 & 6,92 & 2,65 \\
\hline 81 & 7,04 & 1,64 & 15,26 & 1,81 & 3,65 & 2,07 \\
\hline 97 & 8,74 & 1,78 & 14,34 & 1,84 & 2,64 & 2,10 \\
\hline 98 & 7,78 & 1,78 & 18,80 & 1,72 & 4,47 & 2,06 \\
\hline 99 & 7,92 & 1,76 & 27,16 & 1,53 & 13,67 & 1,87 \\
\hline 140 & 9,11 & 1,82 & 9,51 & 1,68 & 3,71 & 1,78 \\
\hline 141 & 8,27 & 1,85 & 2,72 & 2,28 & 0,12 & 1,90 \\
\hline 142 & 7,80 & 1,74 & 25,86 & 1,56 & 9,46 & 2,01 \\
\hline 143 & 7,92 & 1,74 & 7,12 & 2,07 & 0,24 & 1,98 \\
\hline 144 & 9,66 & 1,80 & 10,62 & 1,95 & 6,96 & 2,01 \\
\hline 145 & 8,68 & 1,87 & 8,64 & 2,06 & 2,87 & 2,11 \\
\hline 146 & 8,65 & 1,86 & 7,34 & 2,07 & 2,47 & 2,07 \\
\hline 147 & 7,73 & 1,75 & 11,47 & 1,94 & 4,43 & 2,10 \\
\hline 148 & 8,55 & 1,75 & 8,85 & 2,06 & 3,35 & 2,25 \\
\hline 149 & 9,06 & 1,78 & 21,52 & 1,75 & 17,51 & 1,87 \\
\hline 150 & 8,83 & 1,75 & 24,57 & 1,73 & 17,83 & 1,95 \\
\hline 151 & 9,46 & 1,71 & 11,06 & 1,99 & 4,40 & 2,24 \\
\hline 152 & 9,52 & 1,75 & 15,83 & 1,91 & 9,27 & 2,14 \\
\hline 153 & 10,65 & 1,76 & 27,36 & 1,65 & 18,78 & 1,80 \\
\hline 154 & 8,56 & 1,76 & 11,60 & 2,00 & 1,41 & 2,43 \\
\hline 155 & 9,13 & 1,73 & 13,04 & 1,91 & 1,98 & 2,32 \\
\hline 156 & 8,99 & 1,79 & 17,12 & 1,74 & 10,87 & 1,88 \\
\hline 157 & 8,3 & 1,80 & 15,77 & 1,81 & 5,52 & 2,01 \\
\hline \multicolumn{7}{|c|}{ Mineração (MR) } \\
\hline 91 & 8,99 & 1,72 & 21,21 & 1,69 & 15,23 & 1,87 \\
\hline 92 & 7,41 & 1,77 & 18,46 & 1,75 & 12,70 & 1,93 \\
\hline 93 & 7,95 & 1,72 & 27,49 & 1,52 & 13,02 & 1,89 \\
\hline 95 & 8,01 & 1,70 & 14,50 & 1,84 & 1,44 & 2,14 \\
\hline 117 & 8,37 & 1,74 & 18,85 & 1,72 & 3,92 & 2,15 \\
\hline 118 & 8,08 & 1,74 & 19,09 & 1,71 & 5,82 & 2,10 \\
\hline 119 & 8,02 & 1,73 & 6,24 & 2,11 & 0,18 & 2,20 \\
\hline 120 & 7,75 & 1,72 & 17,11 & 1,76 & 6,37 & 2,10 \\
\hline 121 & 8,25 & 1,77 & 22,14 & 1,65 & 12,26 & 1,91 \\
\hline 122 & 7,60 & 1,76 & 26,51 & 1,54 & 15,06 & 1,82 \\
\hline 123 & 8,99 & 1,74 & 16,13 & 1,84 & 7,66 & 2,13 \\
\hline \multicolumn{7}{|c|}{ Mineração (MA) } \\
\hline 67 & 9,44 & 1,76 & 16,13 & 1,84 & 9,88 & 2,05 \\
\hline 68 & 7,74 & 1,75 & 26,20 & 1,55 & 2,76 & 2,21 \\
\hline 69 & 10,19 & 1,71 & 11,02 & 1,96 & 2,28 & 2,20 \\
\hline 70 & 9,34 & 1,71 & 20,24 & 1,66 & 11,53 & 1,90 \\
\hline 106 & 7,69 & 1,72 & 25,34 & 1,56 & 16,37 & 1,78 \\
\hline 107 & 8,54 & 1,75 & 31,18 & 1,43 & 13,42 & 1,88 \\
\hline 108 & 8,13 & 1,72 & 17,78 & 1,75 & 7,77 & 2,06 \\
\hline 109 & 8,30 & 1,68 & 9,50 & 2,02 & 1,50 & 2,26 \\
\hline 110 & 8,53 & 1,73 & 13,15 & 1,90 & 5,47 & 2,16 \\
\hline 111 & 8,61 & 1,74 & 21,12 & 1,67 & 13,39 & 1,89 \\
\hline
\end{tabular}


A variação da absorção de água (AA) e do conteúdo de $\mathrm{CaO} \%$ com a porcentagem da perda ao fogo normalizada $[\mathrm{PF}]_{\mathrm{N}}$ para os três grupos analisados pode ser visualizado na figura 10.
Para baixas concentrações de sódio as diferenças entre as temperaturas $\left(1070^{\circ} \mathrm{C}\right.$ e $\left.1120^{\circ} \mathrm{C}\right)$ foram pouco influenciadas por outros componentes (Figura 10A), uma vez que o teor de $\mathrm{K}_{2} \mathrm{O}$ contido nas illitas encontra-se em torno de $2 \%$.
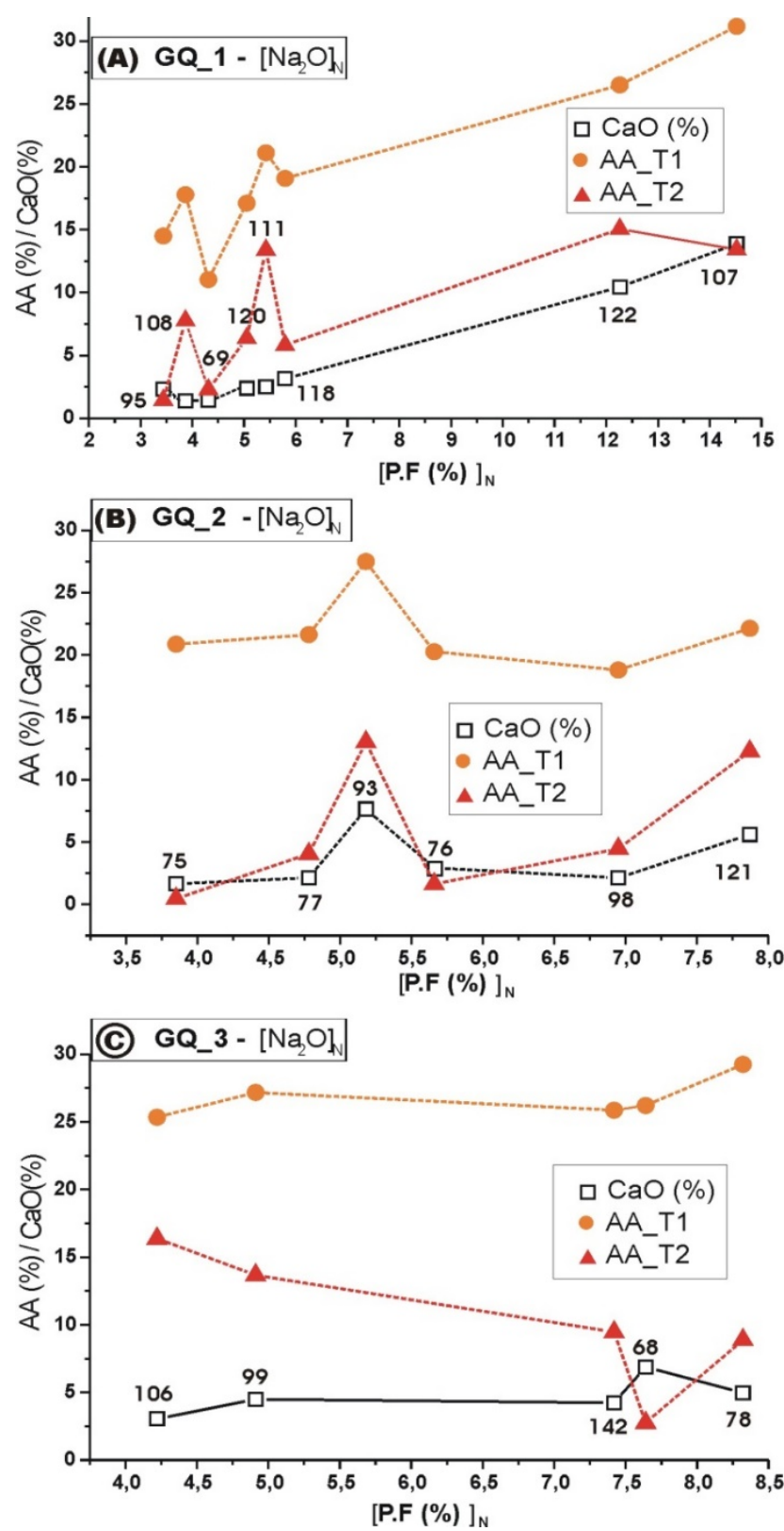

Figura 10 - (a) Variação da absorção de água e concentração de CaO\% com o valor da perda ao fogo [P.F. $]_{N}$ : grupo GQ 1 no intervalo $\left[\mathrm{Na}_{2} \mathrm{O}\right]_{\mathrm{N}}$ de 1,99 a 2,45; grupo GQ 2 no intervalo $\left[\mathrm{Na}_{2} \mathrm{O}\right]_{\mathrm{N}}$ de 3,05 a 3,46\%; grupo GQ 3 no intervalo $\left[\mathrm{Na}_{2} \mathrm{O}\right]_{\mathrm{N}}$ de 3,96 a 4,43 .

Esta comparação é possível devido ao baixo conteúdo de feldspato de potássio, o qual não foi detectado na difração de raios $\mathrm{X}$. As amostras (108, 69 e 111) apresentam queda menos acentuada nos valores de AA, por apresentarem valores menores de $\mathrm{Na}_{2} \mathrm{O}(1,99,2,02$ e 2,05\%, respectivamente - Tabela 1 ) em relação as amostras (95, 120 e 118) com valores de $\mathrm{Na}_{2} \mathrm{O}$ de 2,34, 2,45 e 2,22\% (Tabela 1), respectivamente. As amostras (122 e 107), contém mais de 10\% de
$\mathrm{CaO}$ e porosidade alta, podendo formar silicatos de cálcio em uma temperatura maior.

O grupo (GQ 2) apresenta aspecto semelhante a GQ 1 , sendo que em GQ 2 as amostras (93 e 121) contém mais carbonato e menor teor de sódio em relação às outras amostras do grupo com valores de $3,45 \pm 0,05$ de $\mathrm{CaO} \%$.

O grupo GQ 3 cujo conteúdo de $\mathrm{Na}_{2} \mathrm{O}$ é maior $(3,9 \pm 0,2)$ apresenta aumento continuo na variação da AA, entretanto a amostra 68 se 
desloca da sequência, provavelmente pelo maior conteúdo de $\mathrm{CaO}(6,87 \%)$ e de $\left(\mathrm{Na}_{2} \mathrm{O}+\mathrm{K}_{2} \mathrm{O}\right)$ $(6,24 \%)$, ou seja, mais fundentes poderão incorporar o cálcio na fase fluída melhorando a sinterização (Barba et al, 1997, Van Vlack, 1973). Esta amostra é classificada como siltito arenoso com teor de $\mathrm{CaO}$ de 6,89\% e sílica relativamente baixa $(59,69 \%)$. Isto resulta da cristalinidade da calcita e albita assim como do conteúdo de quartzo, conforme DRX da amostra total (Figura 11) onde as amostras vizinhas (142 e 78), muito próximas entre si, contém dolomita no lugar de calcita $(4,16 \%$ e $4,33 \%$ de $\mathrm{MgO}$ respectivamente), mineral mais resistente à decomposição, apresentando granulometria mais grossa, tendo sido classificados como arenitos.

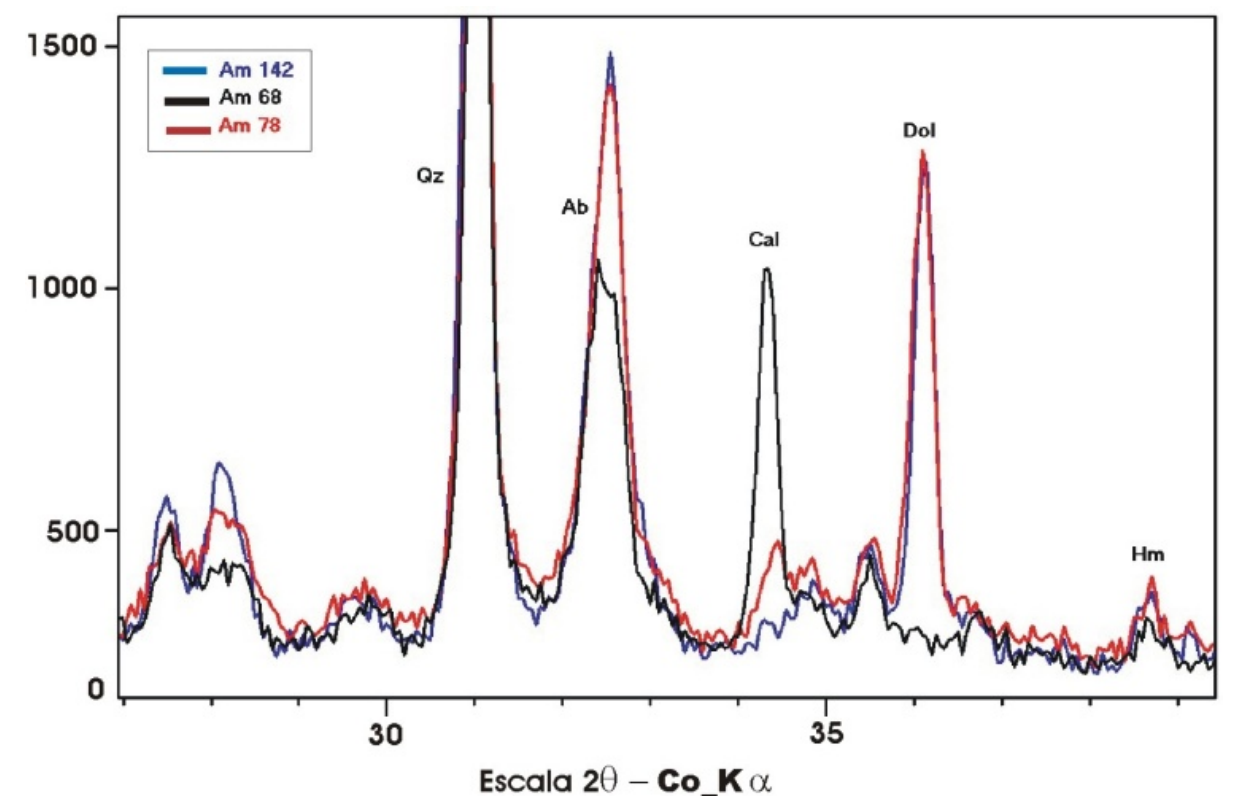

Figura 11 - Gráfico de difração de raios X (amostra total) das amostras 142, 68 e 78 do grupo GQ 3 [Qz=quartzo, Ab=albita, Cal=calcita, Dol=dolomita, $\mathrm{Hm}=$ hematita].

\section{CONCLUSÕES}

As análises geoquímicas das rochas sedimentares argilosas permitiram extrair informações importantes sobre a mineralogia e o estado de alteração, tendo como parâmetros a perda ao fogo, teor de carbonatos e conteúdo relativo de elementos positivos representados pela soma da proporção catiônica em cada amostra. Não foi considerada a presença de outros carbonatos como a dolomita $\left(\mathrm{CaCO}_{3} \cdot \mathrm{MgCO}_{3}\right)$, de ocorrência frequente e que aumenta a perda ao fogo, pois o magnésio está contido em vários minerais formadores de argilas, não sendo possível seu isolamento.

As sequências de amostras identificadas e discutidas mantém uma relação que depende da qualidade e quantidade de minerais, especialmente de carbonatos e argilominerais que os associam de maneira diferenciada.

Os minerais quartzo, feldspatos e argilominerais contêm elementos comuns, porém o grau de alteração pode ser visualizado através de relações que levam em consideração o conteúdo de cátions, uma vez que os processos intempéricos promovem a decomposição e mobilização dos elementos componentes, alterando a concentração dos mesmos e formando compostos mais hidratados que aumentam o valor da perda ao fogo.

A contribuição das illitas é variável e sua transformação pode ser avaliada observando o conjunto de argilominerais os quais indicam uma sequência de evolução e intensidade de alteração. As amostras não carbonáticas mostram alteração crescente de S-III a S-V, a qual está associada principalmente a cloritas em S-III, a clorita e estruturas estratificadas em S-IV e a caulinita na sequência $S-V$. As estruturas estratificadas dos argilominerais são irregulares, sendo mais evidentes nas amostras não carbonáticas, em parte porque a presença destes diminui a porcentagem dos outros compostos.

As sequências analisadas, quando submetidas a temperaturas maiores que $1000^{\circ} \mathrm{C}$ como as utilizadas neste estudo, podem ter influência de elementos fundentes como o sódio e o potássio encontrado nas illitas. 
Com o aumento das temperaturas, outros elementos são incorporados à fase fluída, tais como o $\mathrm{CaO}$ conforme amostra 68, lembrando que a intensidade das reações também depende da compactação dos corpos de prova e da distribuição granulométrica.

\section{REFERÊNCIAS}

ABNT-Associação Brasileira de Normas Técnicas. NBR 13818:1997. Placas Cerâmicas para Revestimentos Especificações e Métodos de Ensaios. Rio de Janeiro, 1997.

BARBA, A.; BELTRÁN, V.; FELIU, C.; GARCÍA, J.; GINÉZ, F.; SÁNCHEZ, E.; SANZ, V. Matérias primas para la fabricación de soportes de baldosas cerâmicas, Instituto de Tecnologia Cerâmica (ITC), Castellón, España, 291p.,1997.

COSTA, M.N.S. Diagênese e alteração hidrotermal em rochas sedimentares da Formação Corumbataí, permiano Superior, mina Granusso, Cordeirópolis/SP. Rio Claro, 2006. Tese (Doutorado), Instituto de Geociências e Ciências Exatas, Universidade Estadual Paulista. 134p.

CHRISTOFOLETTI, S.R.; MORENO, M.M.T.; BATEZELLI, A. Análise de fácies da Formação Corumbataí (Grupo Passa Dois - Bacia do Paraná, Neopermiano) com vista ao emprego na indústria de revestimento cerâmico. Revista Brasileira de Geociências, v. 36, n. 3, p. 488-498, 2006.

FAUER, G. Principles and aplications of inorganic geochemistry. Prentice Hall, New Jersey, 626p., 1991.

MORENO, M.M.T.; ZANARDO, A.; ROCHA, R.R.; ROVERI, C.D. Matéria Prima da Formação Corumbataí na região do pólo cerâmico de Santa Gertrudes, SP, com características naturais para fabricação de argila expandida. Cerâmica, v. 58, p. 342-348, 2012.

MORENO, M.M.T.; ROVERI C.D.; GODOY, L.H.; ZANARDO, A. Caracterização de argilas e composição de massas cerâmicas preparadas com base na análise de curvas de consistência de misturas argila-água. Cerâmica, v. 62, p. 21-31, 2016.

REED, J.S. Principles of Ceramics Processing, John Wiley \& Sons, New York, $2^{\text {nd }}$ ed, 658p.,1995.

ROLLINSON, H.R. Using Geochemical Data: Evaluation, Presentation, Interpretation. Longman Publishers Ltda., Singapore, 362p., 1995.

SOUZA SANTOS, P. Tecnologia de Argilas. Edgard Blücher Edta, v.1, 2a. Ed. São Paulo, Brasil, 408p., 1989.

VAN VLACK, L.H. Propriedades dos Materiais Cerâmicos. Edgard Blücher Edta, São Paulo, Brasil, 318p., 1973

Submetido em 6 de janeiro de 2017 Aceito em 30 de janeiro de 2017 